\title{
Light-Weight Aluminum-Based Alloys-From Fundamental Science to Engineering Applications
}

\author{
Martin Franz-Xaver Wagner \\ Institute of Materials Science and Engineering, Chemnitz University of Technology, Erfenschlager Str. 73, \\ 09125 Chemnitz, Germany; martin.wagner@mb.tu-chemnitz.de; Tel.: +49-371-531-36153 \\ Received: 6 April 2018; Accepted: 10 April 2018; Published: 11 April 2018 \\ check for \\ updates
}

Keywords: aluminum alloys; aluminum matrix composites; aluminum-magnesium composites; severe plastic deformation; ultrafine-grained materials; equal-channel angular pressing; forming technology; materials science; surface engineering; mechanics and modeling

\section{Introduction and Scope}

Academia and industry alike are faced with an ever-growing demand for energy-efficiency and reduced mass. Aluminum-based light-weight materials offer great potential for novel engineering applications, particularly when they are optimized to exhibit high strength and yet provide sufficient reliability. The last decade has thus seen substantial activity in the research fields of high-strength aluminum alloys and aluminum-based composite materials. For twelve years, backed by substantial funding of the German Research Foundation (Deutsche Forschungsgemeinschaft, DFG, Bonn, Germany), scientists of the Collaborative Research Center "High-strength aluminum-based light-weight materials for safety components" (SFB 692) at TU Chemnitz, Germany, have contributed to this research area. Our research efforts have been focused on three main areas: ultrafine-grained (UFG) aluminum alloys produced by severe plastic deformation; aluminum matrix composites (AMCs); and aluminum-based composite materials (including material combinations like magnesium/aluminum or steel/aluminum and the corresponding joining and forming technologies). The framework of SFB 692 has served as a basis for numerous scientific collaborations between scientists from the fields of materials science, design engineering, forming technology, production engineering, mechanics, and even economics-in Chemnitz, and with many well-established experts throughout the world. This Special Issue, comprising 15 scientific papers, represents a joint effort to provide a broad overview of our research activities in the field of aluminum-based light-weight materials, and to bring some recent and relevant results to the attention of a wider international audience.

\section{Contributions}

A key topic studied in the Research Center is the science and engineering of ultrafine-grained materials produced by severe plastic deformation (SPD), where large amounts of plastic deformation at room temperature lead to a gradual formation of very fine grains via the stages of accumulation of dislocations in cell walls and the formation of small and large angle grain boundaries [1]. Over the years, advances in the field of SPD processing [2,3] have strongly influenced the scientific approach of our Chemnitz consortium. Three main SPD techniques are well established by now-accumulative roll bonding (for the production of UFG sheet materials), high pressure torsion (for the generation of small sample volumes with grain sizes down to a couple of nanometers or even into the amorphous state), and equal-channel angular pressing (ECAP). The latter method, pioneered in the early 1980s in Russia [4,5], has become the flagship process of Chemnitz's materials engineers. Even today, ECAP represents the only viable approach that provides relatively large volumes of bulk UFG materials—an 
important requirement for industrial applications that can then exploit the high strength of these UFG structural materials. We have put much effort into up-scaling of our ECAP dies to industrially relevant scales [6,7]-in fact, with a cross-section of $50 \times 50 \mathrm{~mm}^{2}$, our researchers have access to an experimental setup that is one of the largest ECAP dies in the world.

Several papers in this Special Issue deal with ECAP and related SPD methods. Horn et al. [8] address heterogeneous shear deformation during ECAP. While nominally, the simple shear occurring in the ECAP die's shear zone is expected to be homogeneous, the formation of shear bands adjacent to less deformed matrix bands in a regular pattern is an interesting experimental phenomenon that raises questions on the (macro-scale) homogeneity of conventional ECAP billets. The paper summarizes a careful modeling approach that leads to a close agreement with experimental findings. Moreover, the authors' interpretation of the deformation mode in the light of bifurcation analysis may well lead to a more general description of shear instabilities during ECAP. The paper by Fritsch et al. [9] deals with low-temperature ECAP-a technique that makes it possible to process an AA7075 alloy that is not sufficiently ductile to deform by ECAP at room temperature. The paper's main focus is on the positive effects of suitable heat treatments prior to ECAP processing, highlighting the effect of precipitates on grain refinement during subsequent, low-temperature deformation. Berndt et al. [10] move beyond the conventional understanding of SPD processing as a simple deformation that maintains the macroscopic geometry of a billet. They report on low-temperature extrusion of an AA6060 alloy, exploring the idea of producing fine-grained or even UFG microstructures while generating billet shapes that can, in principle, be more complex than conventional ECAP billets with square or circular cross-sections. While a low-temperature extrusion process leads to microstructural gradients that can be partially homogenized by subsequent aging heat treatments, gradation extrusion, as described in the paper by Frint et al. [11], represents a forming technique that explicitly aims at creating distinct gradients. The method, developed at the Chemnitz Fraunhofer Institute for Machine Tools and Forming Technology (IWU), limits SPD to the surface regions, and hence produces billets that are fine-grained at the surface, but coarse-grained (and hence more ductile) in the center.

Magnesium alloys exhibit an even lower density than aluminum alloys, but are prone to corrosion. An obvious solution is to combine magnesium and aluminum alloys in a component, for instance, by cladding the aluminum part around a magnesium core. This approach is discussed in detail by Förster et al. [12], who performed both co-extrusion and die-forging experiments in combination with detailed numerical analysis to fully model the entire processing chain. Intermetallic phases are likely to form when different alloys are joined at elevated temperatures to produce a macroscopic component, and the growth and fragmentation of such phases play an important role during forming of the aluminum/magnesium compounds studied in our Research Center. Kirbach et al. [13] investigate the properties of the corresponding boundary layers from a fracture mechanics perspective. When dealing with UFG microstructures, thermal stability becomes an important factor, and high temperatures often cannot be used for joining processes. Consequently, Habisch et al. [14] study the potential of diffusion-bonding of aluminum alloys and magnesium with different interlayer materials. Scherzer et al. [15] report on a different kind of component; they present dedicated Finite Element simulations of the Presta joining process for assembled camshafts. Joining steel and aluminum in such a component is challenging, for instance, because of thermal expansion. The careful simulations presented here allow for a detailed analysis of all forming steps that reproduce even subtle features of the real life process chain.

Using particles (like $\mathrm{SiC}$ ) as reinforcements represents an alternative approach for increasing the strength of aluminum alloys in AMCs. Introducing such particles, of course, leads to all sorts of novel phenomena and materials engineering challenges. In this Special Issue, Härtel et al. [16] analyze the mechanical behavior of an SiC-reinforced AA2017 alloy at different strain rates and temperatures. They document that pronounced localized deformation is related to the growth of Portevin-Le Châtelier bands. Siebeck et al. [17] consider the high-temperature deformation of different AMCs, with a specific focus on the effect of mechanical alloying of small additions of boron on creep 
resistance. Completing the multifaceted investigations on the thermo-mechanical behavior of bulk AMCs, Winter et al. [18] discuss the effects of different sizes and volume fractions of SiC reinforcements, and of testing temperature, on the high cycle fatigue behavior of a reinforced AA2124 alloy.

In many engineering materials, fatigue life can be massively increased by suitable modifications of the surface. The paper by Nestler and Schubert [19] documents how roller burnishing of an AMC can produce high-quality surfaces and also introduce compressive residual stresses, which can be particularly beneficial for improving the fatigue behavior. Surface properties also come into play when wear and corrosion dominate a component's life span. Sieber et al. [20] show that hard anodizing in sulphuric acid is an energy-efficient process that provides good abrasion resistance of conversion coatings. In ever-more complex combinations of materials in machine parts and components, the need may arise to combine AMCs with either aluminum alloys or with steel. Grund et al. [21] analyze how arc brazing can be used as a joining method at relatively low temperatures in such cases. As materials scientists and engineers, we are often intrigued when new processing techniques make it possible to produce novel materials with interesting microstructures. This may be particularly true for composite materials, where the sheer number of possible combinations and variations of matrix materials and reinforcements is staggering. Yet, considering properties in relation to costs, many of these materials will never make it into real-world applications. The detailed economic analysis by Schmidt et al. [22], combining technology, user and market analyses, is all the more encouraging: it emphasizes the economic potential of AMCs, particularly related to their high strength and weight reduction.

\section{Conclusions and Outlook}

The Collaborative Research Center SFB 692 has, at this point, reached the funding program's regular limit—so where will we go from here? Research on many of the topics highlighted in this Special Issue will certainly continue in Chemnitz during the coming years. In the field of SPD methods, we have demonstrated that reliable, reproducible application of ECAP still poses many challenges, from materials engineering to physical metallurgy. Likewise, the development of new AMCs with improved properties is far from finished, and light-weight components made of multiple materials, for instance in hybrid structures, are currently a hot topic both for industry and fundamental science. Making materials lighter, yet strong and reliable, will certainly remain an attractive goal for scientific endeavors for many years to come. As former Speaker of the Collaborative Research Center SFB 692, I do hope that this Special Issue promotes the ideas developed in Chemnitz and in our extended scientific network, and that many readers find our papers of sufficient interest to stimulate ideas of their own.

Conflicts of Interest: The author declares no conflict of interest.

\section{References}

1. Hughes, D.A.; Hansen, N. High angle boundaries formed by grain subdivision mechanisms. Acta Mater. 1997, 45, 3871-3886. [CrossRef]

2. Valiev, R. Nanostructuring of metals by severe plastic deformation for advanced properties. Nat. Mater. 2004, 3, 511-516. [CrossRef] [PubMed]

3. Estrin, Y.; Vinogradov, A. Extreme grain refinement by severe plastic deformation: A wealth of challenging science. Acta Mater. 2013, 61, 782-817. [CrossRef]

4. Segal, V.M. Materials processing by simple shear. Mater. Sci. Eng. A 1995, 197, 157-164. [CrossRef]

5. Segal, V.M. Equal channel angular extrusion: From macromechanics to structure formation. Mater. Sci. Eng. A 1999, 271, 322-333. [CrossRef]

6. Frint, P.; Hockauf, M.; Halle, T.; Strehl, G.; Lampke, T.; Wagner, M.F.-X. Microstructural Features and Mechanical Properties after Industrial Scale ECAP of an Al-6060 Alloy; Trans Tech Publications: Zürich, Switzerland, 2011; Materials Science Forum Volumes 667-669; ISBN 9783037850077.

7. Frint, S.; Hockauf, M.; Frint, P.; Wagner, M.F.-X. Scaling up Segal's principle of Equal-Channel Angular Pressing. Mater. Des. 2016, 97. [CrossRef] 
8. Horn, T.D.; Silbermann, C.B.; Frint, P.; Wagner, M.F.-X.; Ihlemann, J. Strain localization during equal-channel angular pressing analyzed by finite element simulations. Metals 2018, 8, 55. [CrossRef]

9. Fritsch, S.; Wagner, M.F.-X. On the effect of natural aging prior to low temperature ECAP of a high-strength aluminum alloy. Metals 2018, 8, 63. [CrossRef]

10. Berndt, N.; Frint, P.; Wagner, M.F.-X. Influence of extrusion temperature on the aging behavior and mechanical properties of an AA6060 aluminum alloy. Metals 2018, 8, 51. [CrossRef]

11. Frint, P.; Härtel, M.; Selbmann, R.; Dietrich, D.; Bergmann, M.; Lampke, T.; Landgrebe, D.; Wagner, M.F.X. Microstructural evolution during severe plastic deformation by gradation extrusion. Metals 2018, 8, 96. [CrossRef]

12. Förster, W.; Binotsch, C.; Awiszus, B. Process Chain for the Production of a Bimetal Component from Mg with a Complete Al Cladding. Metals 2018, 8, 97. [CrossRef]

13. Kirbach, C.; Stockmann, M.; Ihlemann, J. A Fragmentation Criterion for the Interface of a Hydrostatic Extruded Al-Mg-Compound. Metals 2018, 8, 157. [CrossRef]

14. Habisch, S.; Böhme, M.; Peter, S.; Grund, T.; Mayr, P. The Effect of Interlayer Materials on the Joint Properties of Diffusion-Bonded Aluminium and Magnesium. Metals 2018, 8, 138. [CrossRef]

15. Scherzer, R.; Fritsch, S.; Landgraf, R.; Ihlemann, J.; Wagner, M.F.-X. Finite element simulation of the presta joining process for assembled camshafts: Application to aluminum shafts. Metals 2018, 8, 128. [CrossRef]

16. Härtel, M.; Illgen, C.; Frint, P.; Wagner, M.F.-X. On the PLC effect in a particle reinforced AA2017 alloy. Metals 2018, 8, 88. [CrossRef]

17. Siebeck, S.; Roder, K.; Wagner, G.; Nestler, D. Influence of boron on the creep behavior and the microstructure of particle reinforced aluminum matrix composites. Metals 2018, 8, 110. [CrossRef]

18. Winter, L.; Hockauf, K.; Lampke, T. Temperature and Particle Size Influence on the High Cycle Fatigue Behavior of the SiC Reinforced 2124 Aluminum Alloy. Metals 2018, 8, 43. [CrossRef]

19. Nestler, A.; Schubert, A. Roller Burnishing of Particle Reinforced Aluminium Matrix Composites. Metals 2018, 8, 95. [CrossRef]

20. Sieber, M.; Morgenstern, R.; Scharf, I.; Lampke, T. Effect of nitric and oxalic acid addition on hard anodizing of $\mathrm{AlCu}_{4} \mathrm{Mg}_{1}$ in sulphuric acid. Metals 2018, 8, 139. [CrossRef]

21. Grund, T.; Gester, A.; Wagner, G.; Habisch, S.; Mayr, P. Arc Brazing of Aluminium, Aluminium Matrix Composites and Stainless Steel in Dissimilar Joints. Metals 2018, 8, 166. [CrossRef]

22. Schmidt, A.; Siebeck, S.; Götze, U.; Wagner, G.; Nestler, D. Particle-Reinforced Aluminum Matrix Composites (AMCs) - Selected Results of an Integrated Technology, User, and Market Analysis and Forecast. Metals 2018, 8, 143. [CrossRef]

(C) 2018 by the author. Licensee MDPI, Basel, Switzerland. This article is an open access article distributed under the terms and conditions of the Creative Commons Attribution (CC BY) license (http://creativecommons.org/licenses/by/4.0/). 